\title{
Valuing Curriculum Evaluation as Scholarship: A Process of Developing a Community of Scholars (Valoriser l'évaluation de programmes d'études comme forme de scholarship : un processus de création d'une communauté de chercheuses)
}

Betty Tate

North Island College (Retired), betty.tate@shaw.ca

Marilyn Chapman

Vancouver Island University, Marilyn.Chapman@viu.ca

Cheryl Zawaduk

Thompson Rivers University (Professor Emerita), zawaduk@tru.ca

Doris Callaghan

University of British Columbia Okanagan (Professor Emerita), doris.callaghan@ubc.ca

Follow this and additional works at: https://qane-afi.casn.ca/journal

Part of the Curriculum and Instruction Commons, Educational Assessment, Evaluation, and Research Commons, Educational Leadership Commons, Higher Education and Teaching Commons, Other Nursing Commons, Other Teacher Education and Professional Development Commons, and the Scholarship of Teaching and Learning Commons

\section{Recommended Citation}

Tate, Betty; Chapman, Marilyn; Zawaduk, Cheryl; and Callaghan, Doris (2018) "Valuing Curriculum Evaluation as Scholarship: A Process of Developing a Community of Scholars (Valoriser l'évaluation de programmes d'études comme forme de scholarship : un processus de création d'une communauté de chercheuses)," Quality Advancement in Nursing Education - Avancées en formation infirmière: Vol. 4: Iss. 1, Article 8.

DOI: https://doi.org/10.17483/2368-6669.1129

This Article is brought to you for free and open access by Quality Advancement in Nursing Education - Avancées en formation infirmière. It has been accepted for inclusion in Quality Advancement in Nursing Education - Avancées en formation infirmière by an authorized editor of Quality Advancement in Nursing Education - Avancées en formation infirmière. 


\section{Valuing Curriculum Evaluation as Scholarship: A Process of Developing a Community of Scholars (Valoriser l'évaluation de programmes d'études comme forme de scholarship : un processus de création d'une communauté de chercheuses)}

\section{Cover Page Footnote}

The authors wish to thank colleagues, students, and practice partners who contributed to curriculum evaluation and scholarship development across the collaborative. Les auteures aimeraient remercier les collègues, les étudiantes et les partenaires des milieux de pratique qui ont contribué à l'évaluation des programmes d'études et au développement du scholarship professoral. 
The Canadian Association of Schools of Nursing (CASN) defines scholarship as encompassing "a full range of intellectual and creative activities that include the generation, validation, synthesis, and/or application of knowledge to advance science, teaching, and practice" (CASN, 2013, p. 2). Throughout the 1990s and early 2000s, the scholarship of teaching, including curriculum evaluation, became increasingly valued and accepted in the nursing academic community (Brookfield, 1995; Carr \& Kemmis, 1986; Eisner, 1991; Storch \& Gamroth, 2002). "In 2002, the BC government announced that by 2005, entry to practice would require a degree in nursing" (Pringle, Green, \& Johnson, 2004, p. 19). The importance of nursing students advancing professional goals by learning about and being guided to engage in scholarship became increasingly evident to nurse educators.

To support this goal, nurse educators were increasingly expected to engage in scholarship (Cash \& Tate, 2008; CASN, 2013; Duncan, 2014; Duncan, Mahara, \& Holmes, 2014; Hawranik \& Thorpe, 2008). This position paper presents how engagement with curriculum evaluation supports the advancement of scholarship from the perspective of four nurse educators. Each nurse educator has 25 years of lived experience with collaborative curriculum evaluation and scholarship while teaching at four different institutions offering a collaborative nursing baccalaureate degree program. Through recollections and reflections, a retrospective story of valuing curriculum evaluation as scholarship is shared.

\section{Integrated Curriculum and Evaluation: Building the Foundation}

The Collaborative Nursing Program of one western Canadian province (CNPBC), later renamed the Collaboration for Academic Education in Nursing (CAEN), implemented in 1992 was designed to increase the offering of baccalaureate education in preparation for licensure as a registered nurse (RN) across the province in response to changing educational requirements (Zawaduk et al., 2014). The collaboration developed a shared curriculum across all program sites where curriculum was defined in part as

the interactions that take place between and among students, clients, practitioners and faculty in a variety of contexts with the intent that learning take place... In this curriculum, students, practitioners, faculty and clients are equally valued as partners in the teaching/learning process. Teachers are seen as expert learners working with students in partnership, in empowering and equitable ways, drawing on student experience and on theory of various kinds to develop the content to be learned. (CAEN, 2015, p. II-4)

The quality of the curriculum focused on co-creation of knowledge rather than a behaviourist approach where the teacher was the expert and the student received specific knowledge based on a designated set of learning outcomes (Bevis \& Watson, 1989). Curriculum and evaluation structures and processes were built upon a set of foundational perspectives that evolved to include phenomenological, critical, and empiricist perspectives (CAEN, 2014).

A phenomenological perspective (Heidegger, 1962; Leonard, 1989; Ray, 1990) considers the nature of human experience as it is lived day-to-day. It attempts to grapple with the interplay of one's existence within one's context or reality (van Manen, 1997). The particular significance of this perspective is the understanding it reveals about the unique nature of a person's experience, including patients and families, students, nurse educators, and practitioners. A phenomenological perspective supported evaluation activities focused on the lived experience of participants engaged within the curriculum. 
Critical perspectives such as critical social theory (Freire, 1990; Habermas, 1971), feminism (Belinky, Clinchy, Goldberger, \& Tarule, 1986; Chinn \& Wheeler, 1985; Gilligan, 1982), and post-colonialism (Anderson, 2004; Doane \&Varcoe, 2015; Peters \& Self, 2005) are concerned with inequities perpetuated by, but not limited to, class, race, gender, colour, and labour. Critical perspectives enable nurses to engage in reflective critique of their practice and the health care cultures in which they practice. Through an understanding of these perspectives, nurses can participate in change processes to prevent the abuse of power, to promote respect, and to be an advocate for the tolerance of diversity and support for social justice (CAEN, 2015). Critical perspectives informed the development of evaluation activities based on reflective critique of teaching and learning related to social justice, diversity, discrimination, inequities, and change processes.

An empiricist approach values "careful scientific strategies that bear results that can be corroborated if not confirmed" (Im \& Meleis, 1999, p. 14). Empirical knowing includes knowledge development of the science of nursing through research, elucidating facts and descriptions, and theoretical premises. The introduction of Carper's (1978) perspective brought forward questions about empirics as the only truth or way of knowing in nursing. Nursing science moved from an empiricist to a post-empiricist stance where total objectivity was questioned (Im \& Meleis, 1999). In a post-empiricist paradigm, students were exposed to the idea that scientific processes can be used for collecting and organizing information while simultaneously understanding that no single truth governs health. Students were encouraged to link the observable to the unobservable (Garrett \& Cutting, 2014; Im \& Meleis, 1999). In the curriculum, multiple ways of knowing were explored by students and educators, and they came to understand that knowledge may be derived from the understanding of self, practice, theory, and scholarship, with each way of knowing informing and influencing the other. An empiricist perspective informed evaluation activities through the development of questionnaires and Likert scale surveys in relation to program completion, graduate follow-up, and practice representative feedback.

The foundational perspectives of the curriculum fostered diversity in the forms and focus of collaborative evaluation activities. These perspectives also informed learning and teaching practices, evaluation processes, scholarship development and influenced how nurse educators across the collaborative program and institutions interacted with one another informally as well as within the formal collaborative processes. The collaborative standing committees, which included Steering, Curriculum, Evaluation, and subsequently Scholarship, fostered relationships and shared decision-making among nurse educators across program sites. Annual conferences and professional development opportunities supported collaboration, curriculum implementation, evaluation practices, knowledge sharing (Duke \& Moss, 2009), scholarship development, and growth as nurse educators.

\section{Curriculum Evaluation: Building Scholarship Skills}

Evaluation practices within the curriculum were grounded in information collection and analysis consistent with foundational perspectives and contextualized by the unique circumstances of students, teachers, practice contexts, and learning environments. The Collaborative Curriculum Evaluation Committee (CCEC) was formed with representatives from all program sites, each bringing their different expertise to curriculum evaluation. Co-creation of evaluation processes occurred as these nurse educators collaborated to develop and implement curriculum evaluation. The inclusion of the foundational curricular and scholarly perspectives 
along with partner commitment to collaboratively develop evaluation principles provided a basis to take up curriculum evaluation as a form of scholarship. These principles of evaluation practice included: (a) developing evaluation plans based on curriculum goals, foundational perspectives, and professional standards that inform curriculum development and revision; (b) designing curriculum evaluation activities from a scholarly perspective informed by evaluation theory, best practices, and evaluation research principles; (c) collecting consistent evaluation data over time with philosophically congruent evaluation methods to provide evidence-informed curriculum change; and (d) committing to inclusivity of nurse educators, students, and practice representatives in evaluation processes (such as providing perspectives, data collection, and meaning making) to foster comprehensiveness and collaboration. Collaborative partners developed evaluation activities based primarily on a scholarly constructivist and responsive approach informed by Guba and Lincoln's (1989) conceptualization of fourth-generation evaluation as it was most consistent with the foundational perspectives of the curriculum. Fourthgeneration evaluation embraced the idea that the evaluation researcher was a subjective partner in knowledge development and acknowledged how human values shape meaning. Knowledge is shaped by human, cultural, social, political, and contextual milieux (Guba and Lincoln, 1989).

The collaborative evaluation plan adopted an orientation that recognized the constructed nature of findings and included students, nurse educators, and practice representatives to empower and enfranchise them (Guba \& Lincoln, 1989). The key design elements of the evaluation framework included

- engaging key stakeholders;

- collectively designing process and summative evaluation methods;

- regular and rigorous review of evaluation practices and tools congruent with foundational perspectives;

- examining how the curriculum fostered student achievement of program goals and entry-level nursing competencies;

- ensuring timely collection and analysis of data;

- using consistent evaluation questions to examine student and graduate cohort practice across time and collaborative sites; and

- sharing collective data across sites and with various stakeholders to inform curricular change.

A summary of findings from multiple data sources across collaborative program sites was regularly reviewed by the Curriculum Committee wherein the need and strategy for curriculum change was discussed, curriculum implementation plans adjusted, and course outlines revised as needed.

Curriculum evaluation from a phenomenological perspective supported nurse educator exploration of the lived experience of students, nurse educators, and nursing practice representatives during curriculum implementation. Process evaluation examined, for example, how well the curriculum was implemented, how learning opportunities and experiences in class and practice settings served to meet curriculum goals, and the lived experience of students, nurse educators, and practice colleagues. One such curriculum goal was to prepare students to "practice nursing within a framework of promoting health and healing through the integration of 
the art and science of nursing within a variety of contexts and with diverse client populations" (CAEN, 2015, p. II-6). Given the integrated nature of a concept-based curriculum wherein concepts such as health promotion, art and science of nursing, context, diversity, and client were threaded across courses and semesters, students at regular semester reviews were asked questions concerning course integration/connectedness, the degree to which the practice context related to the concepts of study, and what redundancies may have occurred across courses and semesters. Summaries of semester reviews were shared at the collaborative annual conference and nurse educators from across sites examined similarities and differences in student experiences and outcomes against the course and program goals (Zawaduk et al., 2014).

A unique example of a phenomenologically based process evaluation was the idea of a "lived experience" forum proposed by a student representative to a partner site curriculum evaluation committee. At the forum, students and nurse educators from the four years of the baccalaureate program wrote and shared their curriculum stories and experiences. The forum generated a broad and shared understanding of the curriculum across the years and deepened participants' understanding of how students evolve as nurses. Senior students and nurse educators had an opportunity to hear how students developed over the four years and junior students learned more about the professional growth and challenges they were likely to experience in the program. The forum also highlighted common issues across a four-year program (Zawaduk \& Heaslip, 2000).

An additional example wherein a phenomenological lens was used in a process-based evaluation activity was at an annual collaborative conference where nurse educators and students from various sites attended. The CCEC facilitated focus groups across the partner sites to foster the understanding of the lived experience of participants. Open-ended questions elicited the rewards and challenges of nurse educators and students being in relationship as a key curriculum component. One challenge for nurse educators was navigating the tension of being in relationship with students while also being responsible for assessing student performance. This identified tension became the basis for further evaluation studies on student evaluation practices. Focus groups not only provided rich data for curriculum evaluation purposes but also gave an opportunity for nurse educators to develop focus group skills as they designed, led, and thematically analyzed focus group narratives.

A second curricular goal was to prepare graduates to "influence the current reality and future of nursing practice and health care at the economic, political, social, environmental and professional levels by anticipating and responding to the changing needs of society" (CAEN, 2015, p. II-6). Curriculum evaluation from a critical perspective fostered reflective critique on curriculum, teaching practices, and practice contexts that focused on issues such as power, diversity, gender, socioeconomics, and colonization and shaped questions that addressed these issues. For example, in a summative survey designed around program goals and professional competencies, graduates were asked how well they thought the curriculum prepared them to attend to the inequities within relationships. In questionnaires and focus groups, students were asked to critique their experiences and, in narratives, describe how the culture of a particular place or how positional power of certain individuals, combined with their desire to perform well in a practice context in part to enhance their employment opportunity, could diminish their confidence in attending to inequities in relationships.

Empiricist perspectives influenced evaluation in the development and analysis of quasiquantitative questionnaires to measure how well the graduates met curriculum goals and 
professional standards. Summative-based questionnaires for graduates and practice representatives (such as nurse preceptors and nurse leaders in particular contexts) upon program completion and for graduates and employers one year post-graduation were designed to identify strengths and areas for curriculum development while also meeting regulatory reporting requirements. Empirical data collected over time and across multiple cohorts facilitated examination of curriculum outcome trends and validated or challenged data from critical and phenomenological perspectives. Additionally, data from critical and phenomenological perspectives provided a rich contextual backdrop for the interpretation of the Likert scale surveys.

Collaborative evaluation processes promoted shared pedagogical knowledge derived from evaluation research, validation of curriculum issues across partner sites, and strengthened the information available to support curriculum change. This collective endeavor included numerous stakeholders (students, nurse educators, practice representatives, professional organizations) and evaluation activities, such as designing evaluation plans, surveys, focus groups, data analysis, and program meetings to stimulate discussion and problem solve on shared issues. The CCEC members reviewed the aggregated process and summative data from across program sites to extrapolate themes and note similarities and differences across various sources of data and to review findings in relation to the overall program goals. The results were used to review and refine the curriculum in order to promote the integration of all concepts and threads, reduce redundancy, and address practice-related issues. Initially, the CCEC chairperson wrote an evaluation report annually for internal uses including accountability, knowledge sharing, and support for curriculum change and external uses such as accreditation or program recognition requirements. This annual report was reviewed by CCEC members for clarity, accuracy, and representation of findings. As the curriculum became increasingly stable after several implementation cycles, fewer full program reviews were required to identify curriculum issues. Summative evaluation activities, therefore, such as program completion and graduate follow-up data collection occurred biennially, and report generation took on a quadrennial pattern. With a stable pattern in the curriculum and full CASN accreditation and professional association recognition, the frequency of several evaluation activities was reduced and evaluation data collection time-lines were lengthened resulting in more available time and growing capacity to focus on curriculum-related research and scholarship development.

Collaboratively designed evaluation plans and approaches served to bring together complementary expertise in knowledge development, inquiry, and scholarship. Each nursing program partner brought different expertise in curriculum evaluation. For example, the university partner was most experienced with curriculum evaluation of a post-diploma baccalaureate in nursing and, given their institutional research mandate, the scholarship of discovery. The college partners with their teaching mandates and familiarity with entry-level RN education were experienced in curriculum evaluation for the purposes of regulatory approval (Zawaduk et al., 2014). Nurse educators learned to redesign curriculum evaluation based on a scholarly, constructivist, and responsive approach (Guba \& Lincoln, 1989); developed research expertise to collect, manage, and interpret copious amounts of evaluation data; acquired skill to disseminate evaluation findings in a scholarly manner; and advanced their ability to foster knowledge translation (such as peer-reviewed presentations and publications). Collaborative aggregated data analysis by the CCEC, shared with other committees and all faculty members, fostered a critical review and an appreciation for different evaluation results across different contexts. Many of these collaborative evaluation activities across multiple nursing programs helped educators to 
understand the unique and site-specific challenges of curriculum implementation and scholarship development. These collaborative experiences contributed to the evolution of scholarship as nurse educators became increasingly engaged in curriculum evaluation processes.

\section{Meeting Expectations: Becoming Scholars}

In the early 2000s, nurse educators in baccalaureate degree entry-level RN programs faced increasing expectations to engage in scholarship by professional accreditation bodies. Likewise, the expectations for scholarship increased as institutional mandates changed from diploma-granting colleges to degree-granting colleges (Dennison, 1992) in the 1990s and subsequently to independent universities in the 2000s (Cowan, 2002). After 10 years of cocreating and implementing curriculum evaluation plans, nurse educators in the collaborative program were prepared to engage with these increased expectations. Boyer's (1990) conceptualization of scholarship that included teaching, integration, application, and discovery influenced and underpinned the development and advancement of scholarship in the collaborative (Storch \& Gamroth, 2002; Zawaduk et al., 2014). Storch and Gamroth (2002) noted that, based on Boyer's ideas, the scholarship of teaching was an "approach to education, carefully planned and continuously examined, wherein teachers are widely read, intellectually engaged, and skilfully building bridges between teaching and learning. It involves dissemination of existing knowledge, as well as creation of new knowledge through interaction" (p. 526). Allen and Field (2005) expanded this definition to address the development of innovative teaching methods and educational materials and the study of teaching and learning. CASN later developed their "Statement on Nursing Scholarship" (2013) which recognized the scholarship of teaching activities based on an "ethic of inquiry in which faculty broadly frame and explore questions related to teaching and learning" (Sawatzky, Enns, Ashcroft, Davis, \& Harder, 2009, p. 262). These developments, evolving from Boyer's (1990) original model, resonated with nurse educators as the definitions offered credibility to activities in which many were engaged: the scholarship of teaching including curriculum evaluation, as well as application and discovery.

The growing interest in linking teaching practices, curriculum evaluation experience, and scholarship within the collaborative led to a funded initiative, the Nurse Educators' Scholarship Project (NESP). This initiative supported the professional development of nurse educators through a community development approach consistent with the curriculum foundational perspectives (Cash \& Tate, 2008). With the intent to create a community of scholars, the project facilitator supported a variety of activities including scholarly support circles, lunch and learn sessions, and writing workshops as well as one-to-one mentoring. Annual scholarship colloquia were held (Cash \& Tate, 2008) to provide a forum for nurse educators to generate and share their scholarship ideas and meet others with similar interests to engage in scholarly projects. These relationships across the collaborative program led to several cross-institutional scholarship projects such as a comparison of collaborative learning units and preceptorship practice models (Callaghan et al., 2009); quality workplace environments for nurse educators (Cash, Daines, Doyle, von Tettenborn, \& Reid, 2009; Cash, Doyle, von Tettenborn, Daines, \& Faria, 2011); and meanings of cultural safety (Cash et al., 2013). The annual collaborative conference that for a decade had focused on curriculum development and evaluation expanded to showcase nurse educator scholarship (Simpson \& Abbott, 2010).

While enacting the evaluation plan, individual partner site CCEC members became increasingly proficient at evaluation scholarship and explored opportunities to engage further in scholarship. For example, one project arising from the curriculum evaluation focus groups that 
uncovered tensions nurse educators experienced when evaluating student performance utilized an institutional ethnography approach, which highlighted how evaluation practices can be based in a taken-for-granted understanding of due process. This study raised ethical issues concerning the practice of student evaluation that was incongruent with the collaborative foundational perspectives (Rankin, Malinsky, Tate, \& Elena, 2010). The corollary work of Malinsky, Dubois, and Jacquest (2010) examined the implications for teaching practices when evaluating students. The committee also explored how nurse educators and students experienced the implementation of a curriculum update in 2007. A multi-year study was designed in which focus group interviews were held with students as they progressed through the updated program and with nurse educators as they revised and implemented courses. These studies represent only a few examples of the growing scholarship across the collaborative program.

Evaluation of the NESP identified that nurse educators increasingly identified as scholars (Cash \& Tate, 2008; Zawaduk et al., 2014) and became aware and embraced their practice of teaching and evaluation as scholarship. Nurse educators examined how to integrate scholarly activities into practice and classroom contexts. For example, in year three and four of the curriculum, students often engaged in inquiry, program evaluation, or community/population assessments with community agencies supervised by nurse educators. Nurse educators became a resource for community inquiry enhancing their own, the students', and the community members' scholarship capacity. Nurse educators in undergraduate programs began to support student applications for funding from the Canadian Institutes of Health Research, provided supervision for these projects, and assisted students to obtain funding to present their scholarship at various conferences.

Developing confidence in their abilities led nurse educators to engage in a broader variety of scholarship including discovery, teaching, application, and integration. Collaborative scholarship and evaluation projects provided for ongoing academic dialogue. Educators increasingly recognized the integration of their teaching, curriculum evaluation, and scholarship, and they furthered their participation in knowledge translation through writing, presenting, and publishing. Across the collaborative program, an increasing engagement in graduate studies at the master's and doctoral levels further contributed to the individual and collective scholarship capacity. The nurse educators' confidence to engage in these scholarly activities was bolstered by involvement in collaborative curriculum evaluation, the scholarship project, and the recognition of themselves as scholars.

Scholarship requires "documentation, peer review and public dissemination, thereby adding new knowledge to a field" (CASN, 2013, p. 2). At a time when nurse educators needed to meet increased expectations for scholarship, experience with collaborative curriculum evaluation provided a solid foundation on which to build. Supportive relationships were in place, nurse educators were experienced in collaborative sharing of expertise across sites, and they had a decade of skill development through participating in documented, peer-reviewed, and publically disseminated curriculum evaluation. The collaborative process brought together unique strengths and expertise in evaluation that fostered innovation in curriculum evaluation and ultimately scholarship to create a community of scholars. 


\section{Concluding Remarks}

A robust curriculum evaluation process within the collaborative facilitated nurse educators to develop shared evaluation activities and innovative teaching practices. However, such activities were initially not recognized nor valued as scholarship. The publishing of Boyer's (1990) work on an expanded definition of scholarship and its gradual acceptance by academia and accreditation bodies contributed to nurse educators identifying several evaluation activities in the realm of scholarship and encouraged them to expand their scholarship beyond teaching to application and discovery.

Adherence to the foundational perspectives upon which the collaborative process was developed was essential to the evolution of curriculum evaluation and scholarship, as was drawing upon the diverse expertise across collaborative colleagues. Curriculum evaluation that was documented, peer-reviewed, and disseminated thereby added new knowledge to the field and became viewed and accepted as a form of scholarship within the collaborative (and beyond). Emphasizing and utilizing phenomenological, critical, and empiricist perspectives, as well as aligning evaluation processes with the concepts of Guba and Lincoln (1989) and community development principles, contributed substantially to the evolution of advanced teaching, evaluation research, and pedagogical inquiry. Increasingly, nurse educators began to view their approach to teaching and evaluation as an opportunity for integrated scholarship rather than an obligation outside of their educator role. The value of collaborative curriculum evaluation as a strong foundation upon which to develop nursing education scholarship across multiple institutions should not be underestimated as a pathway for knowledge development and the recognition of nurse educators as scholars. 


\section{References}

Allen, M. N., \& Field, P. A. (2005). Scholarly teaching and scholarship of teaching: Noting the difference. International Journal of Nursing Education Scholarship, 2(1), 5-23. https://doi.org/10.2202/1548-923x.1094

Anderson, J. M. (2004). Lessons from a postcolonial-feminist perspective: Suffering and a path to healing. Nursing Inquiry, 11, 238-246. https://doi.org/10.1111/j.1440-1800.2004.00231.x

Belinky, M. F., Clinchy, B. M., Goldberger, N. R., \& Tarule, J. M. (1986). Women's ways of knowing. New York, NY: Basic Books.

Bevis, E. O., \& Watson, J. (1989). Toward a caring curriculum: A new pedagogy for nursing. New York, NY: National League for Nursing Press.

Boyer, E. L. (1990). Scholarship reconsidered: Priorities of the professoriate. San Francisco, CA: Jossey-Bass.

Brookfield, S. (1995). Becoming a critically reflective teacher. San Francisco, CA: Jossey-Bass.

Callaghan, D., Watts, W. E., McCullough, D. L., Moreau, J. T., Little, M. A., Gamroth, L. M., \& Durnford, K. L. (2009). The experience of two practice education models: Collaborative learning unit and preceptorship. Nurse Education in Practice, 9(4), 244-252. https://doi.org/10.1016/j.nepr.2008.08.010

Canadian Association of Schools of Nursing [CASN]. (2013). Position statement on scholarship. Ottawa, ON: Author. Retrieved from https://casn.ca/wpcontent/uploads/2014/10/ScholarshipinNursingNov2013ENFINALmm.pdf

Carper, B. A. (1978). Fundamental patterns of knowing in nursing. In L. H.Nicoll (Ed.), Perspectives on Nursing Theory (2nd ed.) (pp. 250-260). Philadelphia, PA: J.B. Lippincott.

Carr, W., \& Kemmis, S. (1986). Becoming critical: Education, knowledge and action research. London, UK: Falmer Press.

Cash, P. A., Daines, D., Doyle, R. M., von Tettenborn, L., \& Reid, R. C. (2009). Recruitment and retention of nurse educators: A pilot study of what nurse educators consider important in their workplaces. Nursing Economic\$, 27(6), 384-389.

Cash, P. A., Doyle, R. M., von Tettenborn, L., Daines, D., \& Faria, V. (2011). Working with nurse educators' collective wisdom: Implications for recruitment and retention. Nursing Economic\$, 29(5), 257-264.

Cash, P. A., Moffitt, P., Fraser, J., Grewal, S., Holmes, V., Mahara, S., ... Nagel, D. (2013). Writing reflexively to illuminate the meanings in cultural safety. Reflective Practice: International and Multidisciplinary Perspectives, 14(6), 825-839. https://doi.org/10.1080/14623943.2013.836086

Cash, P., \& Tate, B. (2008). Creating a community of scholars: Using a community development approach to foster scholarship with nursing faculty. International Journal of Nursing Education Scholarship, 5(1), 1-11. https://doi.org/10.2202/1548-923x.1454

Chinn, P. L., \& Wheeler, C. E. (1985). Feminism and nursing: Can nursing afford to remain aloof from the women's movement? Nursing Outlook, 33(2), 74-77. 
Collaboration for Academic Education in Nursing [CAEN]. (2014). Collaborative curriculum guide. Comox, $\mathrm{BC}$ : Author.

CAEN. (2015). Collaborative curriculum guide. Comox, BC: Author.

Collaborative Nursing Program of British Columbia [CNPBC]. (2004). CNP curriculum guide. Victoria, BC: Author.

Cowan, B. (2002). A history of postsecondary education in British Columbia: Agencies and organizations. New Westminster, BC: Douglas College. Retrieved from http://files.eric.ed.gov/fulltext/ED536089.pdf

Dennison, J. (1992). The university-college idea: A critical analysis. The Canadian Journal of Higher Education, 22(1), 109-124.

Doane, G., \& Varcoe, C. (2015). How to nurse: Relational inquiry with individuals and families in changing health and health care contexts. Philadelphia, PA: Lippincott, Williams \& Wilkins.

Duke, J., \& Moss, C. (2009). Re-visiting scholarly community engagement in the contemporary research assessment environments of Australasian universities. Contemporary Nurse, 32(12), 30-41. https://doi.org/10.5172/conu.32.1-2.30

Duncan, S. (2014). Looking back, moving forward: The promise of nursing in the $21^{\text {st }}$ century. In M. McIntyre \& C. McDonald (Eds.). Realities of Canadian nursing: Professional, practice and power issues (4th ed.) (pp. 451-466). Philadelphia, PA: Wolters Kluwer Health/Lippincott, Williams \& Wilkins.

Duncan, S. M., Mahara, S., \& Holmes, V. (2014). Confronting the social mandate for nursing scholarship - One school of nursing's journey. Quality Advancement in Nursing EducationAvancées en formation infirmière, 1(1), 1-17. https://doi.org/10.17483/2368-6669.1018

Eisner, E. (1991). The enlightened eye: Qualitative inquiry and the enhancement of educational practice. New York, NY: MacMillan.

Freire, P. (1990). Education for critical consciousness. (M. Ramos, Trans.). New York, NY: Continuum.

Garrett, B., \& Cutting, R. (2014). Ways of knowing: Realism, non realism, nominalism and typology revisited with a counter perspective for nursing science. Nursing Inquiry, 22(2), 95-105. https://doi.org/10.1111/nin.12070

Gilligan, C. (1982). In a different voice: Psychological theory and women's development. Cambridge, MA: Harvard University Press.

Guba, E. G., \& Lincoln, Y. S. (1989). Fourth generation evaluation. Newbury Park; CA: Sage.

Habermas, J. (1971). Knowledge and human interest. Boston, MA: Beacon Press.

Hawranik, P., \& Thorpe, K. M. (2008). Helping faculty enhance scholarship. Journal of Continuing Education in Nursing, 39(4), 155-163. https://doi.org/10.3928/0022012420080401-02

Heidegger, M. (1962). Being and time. (J. MacQuarrie \& E. Robinson, Trans.). New York, NY: Harper \& Row. 
Im, E. O. \& Meleis, A. I. (1999). Situation specific theories: Philosophical roots, properties and approach. Advances in Nursing Science, 22(2), 11-34. https://doi.org/10.1097/00012272$\underline{199912000-00003}$

Leonard, V. W. (1989). A Heideggerian phenomenological perspective on the concept of the person. Advances in Nursing Science, 11(4), 40-55. https://doi.org/10.1097/00012272$\underline{198907000-00008}$

Malinsky, L., DuBois, R., \& Jacquest, D. (2010). Building scholarship capacity and transforming nurse educators' practice through institutional ethnography. International Journal of Nursing Education Scholarship, 7(1). https://doi.org/10.2202/1548-923x.1948

Peters, H. I., \& Self, B. (2005). Colonialism, resistance and the First Nations Health Liaison Program. Currents: Scholarship in the Human Services, 4(1).

Pringle, D., Green, L., \& Johnson, S. (2004). Nursing education in Canada: Historical review and current capacity. Ottawa, ON: The Nursing Sector Publishing Company. Retrieved from https://www.nurseone.ca/ /media/nurseone/page-content/pdfen/nursing_education_canada_e.pdf?la=en

Rankin, J. M., Malinsky, L., Tate, B., \& Elena, L. (2010). Contesting our taken-for-granted understanding of student evaluation: Insights from a team of institutional ethnographers. Journal of Nursing Education, 49(6), 333-339. https://doi.org/10.3928/0148483420100331-01

Ray, M. (1990). Phenomenological method for nursing research. In N. L. Chaska (Ed.), The Nursing Profession: Turning points (pp. 173-179). St. Louis, MS: C.V. Mosby.

Sawatzky, J. V., Enns, C., Ashcroft, T. J., Davis, P. L., \& Harder, B. N. (2009). Teaching excellence in nursing education: A caring framework. Journal of Professional Nursing, 25(5), 260-266. https://doi.org/10.1016/j.profnurs.2009.01.017

Simpson, S., \& Abbott, K. (2010). Traditions and transitions: History of the nursing programs at Thompson Rivers University, 1973-2003. Gatineau, QC: Gauvin Press.

Storch, J., \& Gamroth, L. (2002). Scholarship revisited: A collaborative nursing education program's journey. Journal of Nursing Education, 41, 524-530.

van Manen, M. (1997). Researching lived experience: Human science for an action sensitive pedagogy. London, ON: Althouse.

Zawaduk, C., Duncan, S., Mahara, S., Tate, B., Callaghan, D., McCullough, D., ... Van NesteKenny, J. (2014). Mission possible: Twenty-five years of University and College collaboration in baccalaureate nursing education. Journal of Nursing Education, 53(10), 580-588. https://doi.org/10.3928/01484834-20140922-04

Zawaduk, C., \& Heaslip, P. (2000, February). Lived experience across the curriculum: A comparative analysis of methodologies. Paper presented at the CAUSN National Educators Conference, Vancouver: BC. 